\title{
Hepatic Portal Venous Gas in Necrotizing Pancreatitis
}

\author{
Jin-Ming Wu Ming-Yang Wang \\ Division of General Surgery, Department of Surgery, National Taiwan University Hospital, Taipei, Taiwan
}

A 62-year-old woman with a history of diabetes mellitus, hypertension, and end stage renal disease presented at the hospital with severe abdominal pain with involuntary guarding and rebound tenderness. The temperature was $38.7^{\circ} \mathrm{C}$. Laboratory data revealed a white blood cell count of $20.49 \times 10^{9} / 1$, glutamic oxaloacetic transaminase level of $31 \mathrm{U} / \mathrm{l}$, total bilirubin level of $0.32 \mathrm{mg} / \mathrm{dl}$, prothrombin time of $35 \mathrm{~s}$, serum amylase level of 2,085

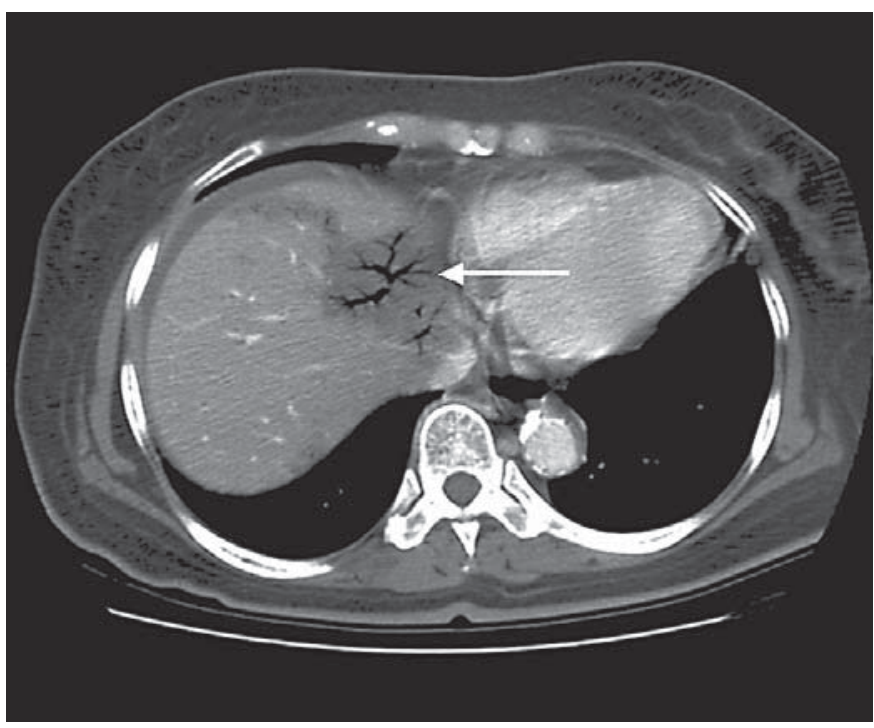

Fig. 1. Computed tomography scan demonstrating a large amount of gas in the hepatic portal venous system and hypo-enhancement of the nearby hepatic parenchyma (arrow).

\section{KARGER}

Fax +41613061234 E-Mail karger@karger.ch www.karger.com
(C) 2009 S. Karger AG, Basel

0253-4886/09/0262-0119\$26.00/0

Accessible online at:

www.karger.com/dsu
$\mathrm{U} / \mathrm{l}$, serum lipase level of 4,063 U/1, creatinine level of 10.8 $\mathrm{mg} / \mathrm{dl}$, and serum urea nitrogen of $120.2 \mathrm{mg} / \mathrm{dl}$. Arterial blood gas analysis showed $\mathrm{pH} 7.3, \mathrm{PaCO}_{2} 28.5 \mathrm{~mm} \mathrm{Hg}$, bicarbonate $13.6 \mathrm{mmol} / \mathrm{l}$, and base excess $-11.4 \mathrm{mmol} / \mathrm{l}$. Abdominal computed tomography showed a large amount of gas in the left hepatic portal venous system (fig. 1, arrow) and irregular enhancement of pancreas with fluid accumulation. Emergent exploratory laparot-

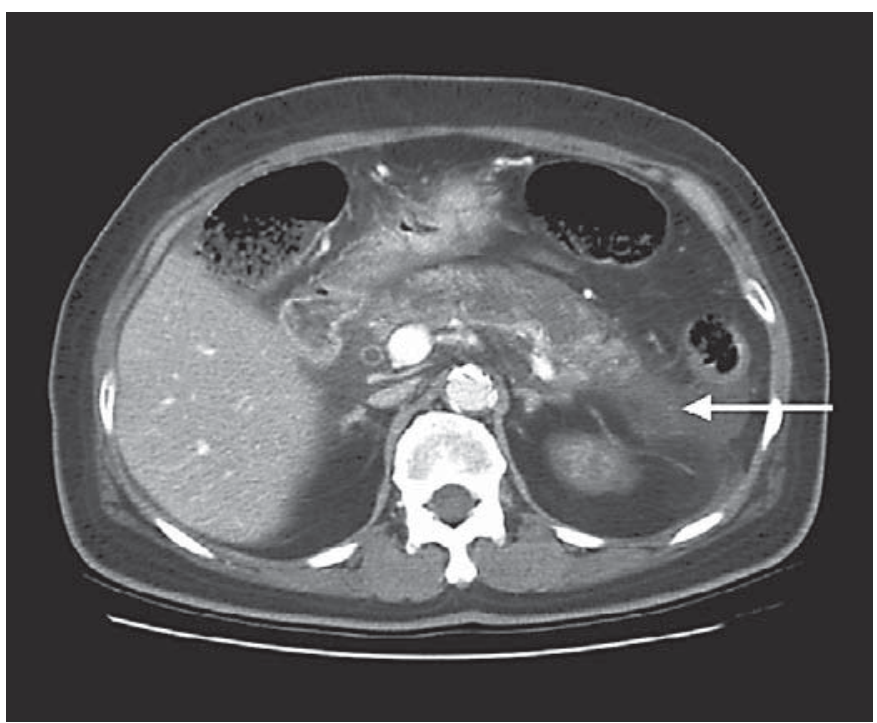

Fig. 2. Computed tomography scan demonstrating irregular enhancement of pancreas with fluid accumulation, extending to the left pararenal spaces (arrow). 
omy revealed necrotic change of the pancreatic body and tail with bloody fluid accumulation (fig. 2, arrow). Gross examination of the small and large bowels was healthy. Drainage of peripancreatic area was done. One month later, the value of amylase and lipase became decreased gradually, and oral intake was resumed smoothly.

Hepatic portal venous gas (HPVG) was first described in 1955 by Wolf and Evans [1]. Most cases of HPVG are caused by mesenteric vascular occlusion and subsequent bowel necrosis. However, HPVG may occur with rare conditions, including digestive tract dilatation, inflammatory bowel disease, gastric ulcer, complication of endoscopic procedures, and necrotizing pancreatitis [2]. The etiology of HPVG in this case may be shock-induced mucosal injury, which caused air to enter small mesenteric veins. HPVG is not a disease but a diagnostic clue in patients who may be harbouring an intra-abdominal catastrophe. Urgent surgical exploration is indicated in patients associated with acute abdominal pathology.

\footnotetext{
References $\quad 1$ Wolf JN, Evans WA: Gas in the portal veins of the liver in infants: a roentgenographic demonstration with postmortem anatomical correction. AJR Am J Roentgenol 1955; 74:486-489.

2 Liebman PR, Patten MT, Manny J, et al: Hepatic portal venous gas in adults: etiology, pathophysiology, and clinical significance. Ann Surg 1978;187:281-287.
} 